\title{
Bilateral sweat tests with two different methods as a part of cystic fibrosis newborn screening (CF NBS) protocol and additional quality control
}

\author{
Dorota Sands $^{1}$, Mariusz Oltarzewski ${ }^{2}$, Anna Nowakowska ${ }^{1}$, Katarzyna Zybert ${ }^{1}$ \\ ${ }^{1}$ Paediatric Department - Centre CF, Institute of Mother and Child, Warsaw, Poland \\ ${ }^{2}$ Screening Department, Institute of Mother and Child, Warsaw, Poland
}

\begin{abstract}
Infants with positive CF newborn screening (NBS) results are called to a CF Centre for verification. Those, in whom the sweat test is elevated, undergo further medical procedures. The aim of our study was to evaluate the applicability of Nanoduct - a new system measuring sweat conductivity and giving immediate results in a CF NBS protocol. Measurements with Nanoduct were compared with the classic pilocarpine method. During 3 years 487 infants from CF NBS had both sweat tests performed on the same day, at the same CF centre. CF infants had a mean conductivity of $99.8 \pm 18.8$ $\mathrm{mmol} / \mathrm{L}$ and a mean chloride concentration of $74.0 \pm 18.4 \mathrm{mmol} / \mathrm{L}$. Non-CF infants values were $29.8 \pm 7.7 \mathrm{mmol} / \mathrm{L}$ and $19.2 \pm 6.6 \mathrm{mmol} / \mathrm{L}$ respectively. A good correlation between both tests was found $(95 \%$ confidence level (CI); r=0.87). The optimal cut off, based on follow up experience of screened children, for conductivity tests was $50 \mathrm{mmol} / \mathrm{L}$ and for chloride concentration was $34 \mathrm{mmol} / \mathrm{L}$ (no lost CF, 11 false positive) with 100\% sensitivity and 97.5\% specificity. In conclusion Nanoduct is a very useful and reliable tool in CF NBS protocol, allowing more time efficient organization of the diagnostic and training procedures. Simultaneous bilateral sweat testing with two different methods (concentration and conductivity) provides an extra quality control system.
\end{abstract}

Key words: sweat test, conductivity, newborns, cystic fibrosis, screening

\section{Introduction}

National CF NBS started in Poland in September 2006. The programme was introduced and coordinated by the Screening Department and CF Centre in the Institute of Mother and Child and was rolled out across the country. Screening for CF was based on the 3 stage IRT/DNA/IRT protocol. Infants with positive neonatal CF screening results were called to a CF Centre for verification. The same day two sweat tests were performed: classical Gibson-Cook and Nanoduct based on conductivity. Thanks to quick conductivity test results diagnosed infants could pass all the trainings and return home on the same day $[1,2]$.

Measurement of sweat chloride concentration by the quantitative pilocarpine iontophoresis test (QPIT), as described by Gibson and Cook [3,4], is considered

Correspondence: D. Sands, Institute of Mother and Child, Kasprzaka 17a, 01-211 Warszawa, Poland; tel.: (+4822) 3277190, fax.: (+4822) 3277043,

e-mail: dorotasands@onet.eu to be the most accurate method to diagnose $\mathrm{CF}$ and has been accepted as the standard for sweat testing [5]. However, this method involves multiple steps for collection and analysis of the sweat sample and involves the risk of volumetric, gravimetric, condensate and evaporation errors in the procedure. In this context, the measurement of sweat conductivity is an increasingly used method because it is easier to perform and requires a smaller sample than QPIT [6].

Sweat contains a variety of ions which contribute towards measurements of conductivity and osmolarity. Conductivity represents the nonspecific measurements of the total anion activity in a solution and therefore has a higher concentration in sweat than chloride. The reading is displayed in equivalent $\mathrm{NaCl}$ molarity units $(\mathrm{mmol} / \mathrm{L})$ [7]. The determination of conductivity in 
sweat, as a test for approximation to electrolytes in a non selective manner, has been shown to be as effective as the quantitative determination of sweat chloride or sodium concentration $[8,9]$.

Sweat collected in Macroduct coils and transferred to the Sweat-Chek conductivity analyzer (Wescor Inc., Logan, Utah) has been used in some settings. Recently, a new conductivity analyzer, Nanoduct, has been developed for use especially in the neonatal population.

Nanoduct is a new diagnostic system that induces, collects and analyzes sweat in one step while the required electrodes and sensors are attached to the patient [10]. Compared to the sweat volumes between 75 to $100 \mu 1$ required by other systems, this system needs only $3 \mu \mathrm{l}$ of sweat and the results are available within half an hour.

The aim of our study was to evaluate the applicability of Nanoduct, a new system measuring conductivity and giving immediate results in a CF NBS protocol. Nanoduct measurements were compared with classic pilocarpine sweat chloride concentration as reference to assess its accuracy and precision as a diagnostic analytical procedure.

\section{Materials and methods}

Patients. 1057 (528 conductivity and 529 chloride concentration) sweat tests were performed between 01.09.2006 and 01.06.2009 at the CF Centre of the Institute of Mother and Child in Warsaw.

487 infants aged 4-6 weeks with positive results of screening tests (IRT-I over 99.4 percentile and one or two CFTR mutations or IRT-II over cut-off) were called for further evaluation in our CF Centre (sweat tests and specialist consultation). Control included 45 healthy infants 4-8 weeks old, who did not need a recall within CF NBS programme (negative screening result after the first step).

Sweat tests. In the infants two kinds of sweat tests were performed (quantitative pilocarpine iontophoresis and conductometry). Both tests were performed on the same day, by the same qualified personnel. Quantitative pilocarpine iontophoresis chloride was tested according to the Gibson and Cook method [3], i.e. quantitative analyses of sweat chloride by a manual titration using the Schales and Schales mercuric nitrate procedure. This method is well established as the gold standard but is time consuming and open to many risks of error.

In the Nanoduct system continuous flow analysis eliminates a separate collection phase and analyzes samples within minutes [7]. The possibility of human error is significantly reduced. The system provides automatic display of initial sweating rate and automatic averaging of conductivity. With shorter stimulation time and smaller sample requirement (3 microliters of sweat), reliable results are available in a few minutes. Nanoduct's small components fit easily on neonates. It is an integrated diagnostic system that simplifies the procedure for all patients. Nanoduct incorporates the classic method of inducing sweat by pilocarpine iontophoresis. The pilocarpine is carried into the dermis of the patient from Pilogel ${ }^{\circledR}$ Iontophoretic discs via a controlled electrical current supplied by the Nanoduct Inducer/Analyzer. This is followed by continuous flow analysis of sweat electrolyte concentration using the conductivity sensor.

DNA analysis, based mainly on the sequencing of eight $C F T R$ regions, covered 505 CFTR variants including the 16 most common CFTR mutations in the Polish population.
Depending on DNA and sweat tests analysis results, infants were divided into 3 main groups: $\mathrm{CF}$, non- $\mathrm{CF}$ and observational group. $\mathrm{CF}$ group included infants with confirmed diagnosis and known CFTR mutations causing CF, non-CF consisted of the following subgroups: control (healthy infants with negative screening test), healthy infants from CF NBS recall (false positives) and CFTR mutation carriers. Observational group consisted of infants without established diagnosis, who needed further clinical observation, repeated sweat tests and more detailed salt transport investigations, also nasal potential difference (NPD). The observational group consisted of 6 infants. Four of them had the same genotype: F508del/R117H,IVS8-7T/IVS8-9T, one R553X/ R117H,IVS87T/IVS8-7T and one G542X/ R117H, IVS8-7T/IVS8-9T.

The infants had pancreatic function assessed clinically, based on weight gain and stool features with laboratory confirmation by faecal elastase-1. Depending on the results they were described as: pancreatic sufficient (CF/PS) and pancreatic insufficient (CF/PI). Infants from all the other groups were pancreatic sufficient.

Statistical analysis. The results of both sweat tests were assessed statistically using descriptive measures for one variant, centiles, mean, SD, and median. The association of both methods was assessed through the correlation coefficient. The Mann-Whitney U test was applied for pair wise group comparison. Limits of agreement were calculated with $95 \%$ confidence intervals. The capability of the conductivity and QPIT to discriminate between CF and non-CF was assessed by constructing a receiver operating characteristic (ROC) curve and overall accuracy of the best cut-off values was assessed through calculation of sensitivity, specificity, positive predictive value (PPV), negative predictive value (NPV) and kappa coefficient.

\section{Results}

Among 487 infants from CF NBS, in 481 cases both sweat tests were performed. Due to technical reasons 3 infants had no Nanoduct and 3 had no iontophoresis (not enough sweat). A summary of the tests is presented in Table 1 and 2.

There were $45 \mathrm{CF}$ diagnosed children, 6 staying under observation. In the control group of 45 infants, one child had no Nanoduct result. CF infants had a mean conductivity of $99.8 \pm 18.8 \mathrm{mmol} / \mathrm{L}$ (mean $852 \pm 24.2 \mathrm{mmol} / \mathrm{L}$ if pancreatic sufficient-PS versus $106.1 \pm 11.7 \mathrm{mmol} / \mathrm{L}$ if pancreatic insufficient-PI) and a mean chloride concentration of $74.0 \pm 18.4 \mathrm{mmol} / \mathrm{L}$ $(64.3 \pm 19.0 \mathrm{mmol} / \mathrm{L}$ in PS vs. $78.0 \pm 16.8 \mathrm{mmol} / \mathrm{L}$ in PI) (Table 1 and 2). CF children who were pancreatic sufficient had lower (nearer to normal range) values in both tests versus higher values of pancreatic insufficient infants. Non-CF infants values were $29.8 \pm 7.7$ and $19.2 \pm 6.6 \mathrm{mmol} / \mathrm{L}$ respectively. Similar means, medians characterized all non-CF infants whatever was their origin (Table 2). In Mann-Whitney U test p $>0.02$ confirmed no differences between the groups. Nanoduct mean value +3 SD in control group was 50.2 $\mathrm{mmol} / \mathrm{L}$ and mean $+3 \mathrm{SD}$ in healthy infants recalled for sweat tests was $53.4 \mathrm{mmol} / \mathrm{L}$. Chloride concentration mean value $+3 \mathrm{SD}$ was $44.1 \mathrm{mmol} / \mathrm{L}$ in control infants, mean $+3 \mathrm{SD}$ was $39.7 \mathrm{mmol} / \mathrm{L}$ in healthy infants originating from recalls. 
Table 1. Sweat conductivity (Nanoduct) and chloride titration (quantitative pilocarpine iontophoresis) in 3 main groups

\begin{tabular}{|c|c|c|c|c|c|c|c|c|c|c|c|c|}
\hline \multirow{2}{*}{ Group } & \multicolumn{6}{|c|}{$\begin{array}{c}\text { Conductivity } \mathrm{NaCl} \\
\lfloor\mathrm{mmol} / \mathrm{L}\rfloor\end{array}$} & \multicolumn{6}{|c|}{$\begin{array}{c}\text { Chloride tilration } \mathrm{Cl}^{-} \\
\qquad \mathrm{mmol} / \mathrm{L}\rceil\end{array}$} \\
\hline & $\mathrm{N}$ & Mean & $\mathrm{SD}$ & Min & Max & Med. & $\mathrm{N}$ & Mean & SD & Min & Max & Med. \\
\hline $\mathrm{CF}$ & 42 & 99.6 & 19.0 & 57.0 & 126.0 & 105.5 & 45 & 74.0 & 18.4 & 38.8 & 121.3 & 75.6 \\
\hline Non-CF & 480 & 29.8 & 7.7 & 11.0 & 60.0 & 28.0 & 478 & 19.2 & 6.6 & 6.8 & 54.0 & 17.6 \\
\hline obscrvation & 6 & 46.2 & 14.9 & 32.0 & 66.0 & 41.0 & 6 & 33.6 & 13.8 & 16.2 & 49.4 & 36.6 \\
\hline
\end{tabular}

$\mathrm{N}$ - number of tests, Med. - median

Table 2. Sweat conductivity (Nanoduct) and chloride titration (quantitative pilocarpine iontophoresis) in subgroups

\begin{tabular}{|c|c|c|c|c|c|c|c|c|c|c|c|c|}
\hline \multirow[t]{2}{*}{ Group } & \multicolumn{6}{|c|}{$\begin{array}{l}\text { Conductivity } \mathrm{NaCl} \\
\qquad[\mathrm{mmol} / \mathrm{L}\rfloor\end{array}$} & \multicolumn{6}{|c|}{$\begin{array}{l}\text { Chloride titration } \mathrm{Cl}^{-} \\
\qquad \mathrm{mmol} / \mathrm{L}]\end{array}$} \\
\hline & $\mathrm{N}$ & Mean & SD & Min & Max & Med & $\mathrm{N}$ & Mean & SD & Min & Max & Med \\
\hline $\mathrm{CF} / \mathrm{PS}$ & 13 & 85.2 & 24.2 & 57 & 126 & 91 & 13 & 64.3 & 19.0 & 38.8 & 92.1 & 70.6 \\
\hline $\mathrm{CF} / \mathrm{PI}$ & 29 & 106.1 & 11.7 & 67 & 126 & 109 & 32 & 78.0 & 16.8 & 53.3 & 121.3 & 77.7 \\
\hline observation & 6 & 46.2 & 14.9 & 32.0 & 66.0 & 41.0 & 6 & 33.6 & 13.8 & 16.2 & 49.4 & 36.6 \\
\hline Carrier & 142 & 29.5 & 7.7 & 17 & 57 & 28 & 141 & 19.3 & 5.7 & 10.9 & 39.9 & 18.0 \\
\hline Healthy & 294 & 30.1 & 7.8 & 12 & 60 & 28 & 292 & 19.1 & 6.8 & 6.8 & 46.1 & 17.5 \\
\hline Control & 44 & 28.6 & 7.2 & 11 & 46 & 27 & 45 & 19.2 & 8.3 & 11.5 & 54 & 16.2 \\
\hline Total & 528 & 35.5 & 21.0 & 11 & 126 & 29 & 529 & 23.9 & 18.5 & 6.8 & 121.3 & 18.3 \\
\hline
\end{tabular}

$\mathrm{N}$ - number of tests; Med. - median; CF - children with pancreatic sufficiency (CF/PS) and pancreatic insufficiency (CF/PI); Healthy - healthy infants from CF NBS recall (false positives); Control - healthy infants with negative screening test

Optimal level of cut-off values were calculated from receiver operating characteristics (ROC) (Fig. 1 and Fig. 2). Receiver operating characteristics (ROC) curve for conductivity sweat test (Fig. 1) showed the capacity to predict cystic fibrosis diagnosis based on molecular analysis and clinical examination. Optimal cut off based on screened children follow up experience for the conductivity test was $50 \mathrm{mmol} / \mathrm{L}$ (no lost CF, 11 false positive) with $100 \%$ sensitivity, $97.5 \%$ specificity and PPV 79.25 (Table 3). No false positives were found in values over $60 \mathrm{mmol} / \mathrm{L}$. The conductivity values between 50 and $60 \mathrm{mmol} / \mathrm{L}$ were assumed borderline.

Optimal cut off for chloride concentration was established at $34 \mathrm{mmol} / \mathrm{L}$ (no lost CF, 11 false positive) with $100 \%$ sensitivity and $97.5 \%$ specificity (Fig. 2 and Table 4). No false positives were found in the range of values over $46 \mathrm{mmol} / \mathrm{L}$. The chloride levels between 34 and $46 \mathrm{mmol} / \mathrm{L}$ were assumed borderline (Tab. 5).

A good correlation between both tests was found (CI 95\%, r=0.87) (Fig. 3). There were distinctive clusters of positive and negative results.

\section{Discussion}

\section{Conductivity}

Conductivity method provides a very high capacity to identify CF and non-CF [6]. There are two systems for sweat conductivity measurements.

The Macroduct system, which collects sweat into capillary tubing, developed to limit sweat volume loss from evaporation. Allied to conductivity measurements, sweat analysis can be performed on aliquots as small as $5 \mu 1$, on a minimum acceptable sample of $15 \mu \mathrm{l}$ collected over 30 minutes. The collection of pure liquid sweat facilitates the measurements of conductivity, although it is also possible to measure chloride on the sample collected through a capillary system [11]. Studies proving good correlation between chloride concentration and conductivity on the same sample of sweat have been performed [6].

The Macroduct system has been further developed to perform sweat collection and analysis in infants; Nanoduct provides measurements of conductivity on samples as small as $3 \mu \mathrm{l}$. However, unique continuous flow analysis eliminates a separate collection 


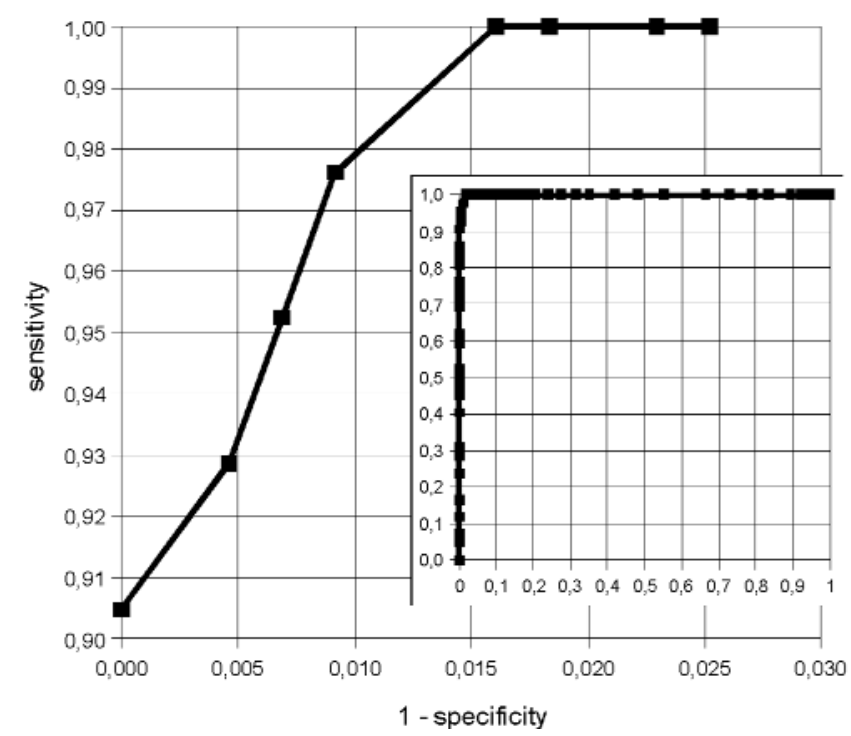

Fig. 1. Receiver operating characteristics curve for conductivity sweat test showing the capacity to predict cystic fibrosis diagnosis (based on molecular analysis and clinical examination). Each filled square represents the cut-off value starting from 50 (lower left corner) to 61 (upper right corner).

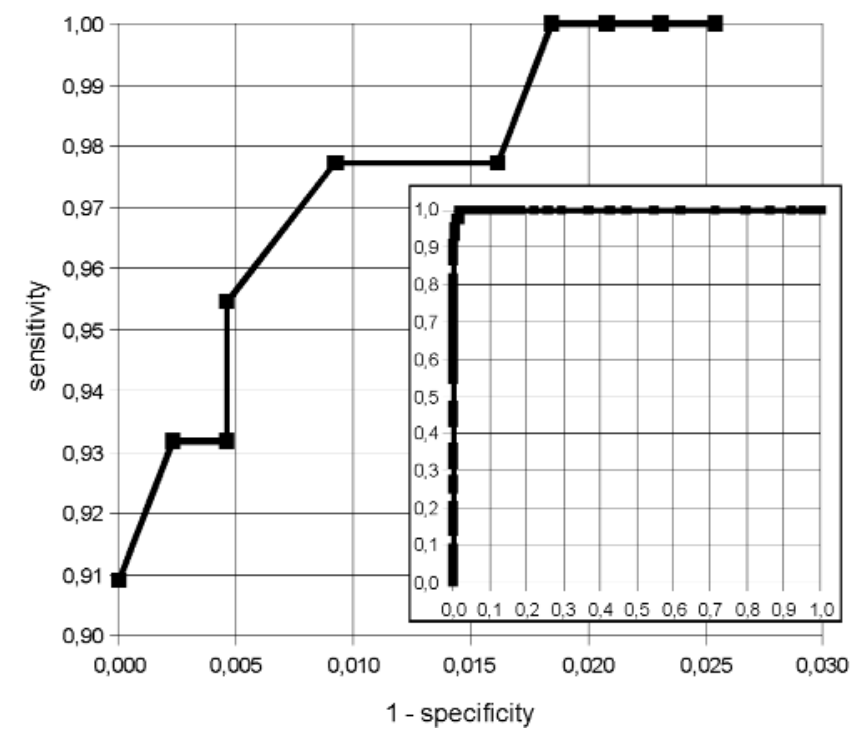

Fig. 2. Receiver operating characteristics curve for chloride titration sweat test showing the capacity to predict cystic fibrosis diagnosis (based on molecular analysis and clinical examination). Each filled square represents the cut-off value starting from 34 (lower left corner) to 47 (upper right corner).

phase and the performance of two different methods on the same sample of sweat is no more possible.

Indeed, the Nanoduct system is more adapted for infants which is why we use it in our screening procedure, although in our pilot CF NBS in the years 19992003 we were working on Macroduct [1].

Although the producer recommends the same reference values for both systems (Macroduct and Nanoduct: 0 to $60 \mathrm{mmol} / \mathrm{L}$ are in the normal range; 60 to 80

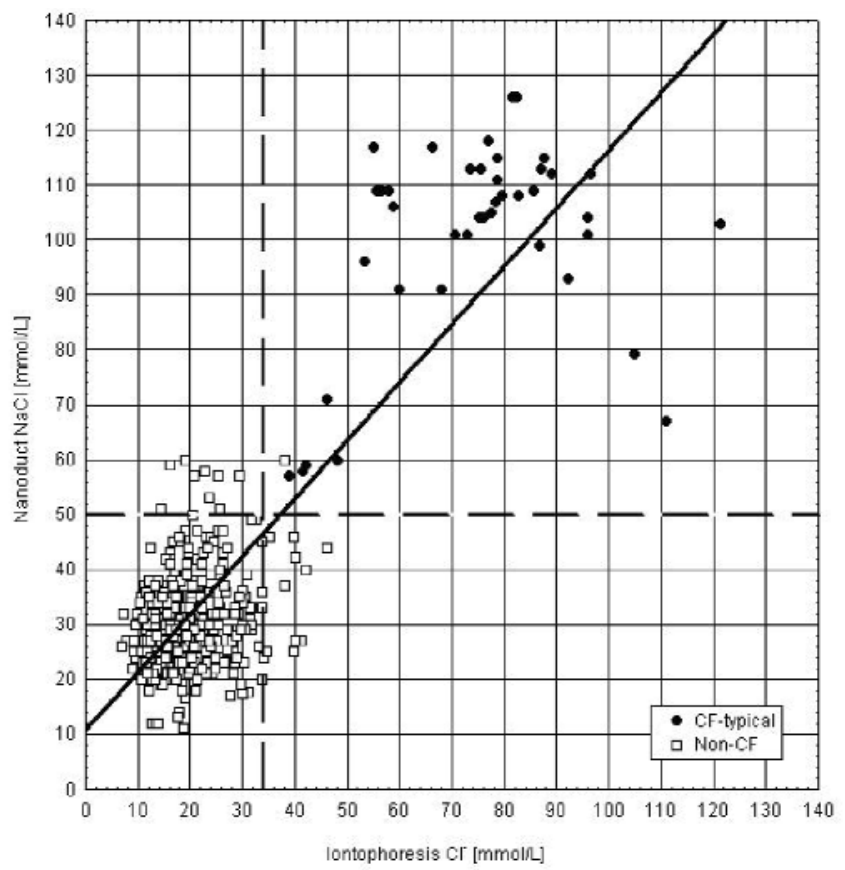

Fig. 3. Correlation between sweat tests results obtained with the conductivity method (Nanoduct) and chloride titration (Iontophoresis); $\mathrm{N}=522, \mathrm{r}=0.87, \mathrm{CI} 95 \%$. $\mathrm{N}$ - number of tests. $\mathrm{r}$ - correlation coefficient. $\mathrm{CI}$ - confidence interval.

$\mathrm{mmol} / \mathrm{L}$ are borderline; and readings above $80 \mathrm{mmol} / \mathrm{L}$ should be considered abnormal) discussing the results of different studies the system used is always mentioned [7].

In Lezana study (Macroduct) on mixed age group, results were as follow: conductivity $\geq 90 \mathrm{mmol} / \mathrm{L}$ confirmatory, value $<75 \mathrm{mmol} / \mathrm{l}$ negative, values $75-89$ $\mathrm{mmol} / \mathrm{L}$ corresponded to the equivocal range [6]. According to our data it could not be applied for infants.

Barben's group [12] working on Nanoduct in the mixed age group found $59 \mathrm{mmol} / \mathrm{L}$ as an upper limit of normal conductivity, so also higher than our infants data $(50 \mathrm{mmol} / \mathrm{L})$. He reported median conductivity for CF $115 \mathrm{mmol} / \mathrm{l}$, non-CF $37 \mathrm{mmol} / \mathrm{L}$, while in our infant population the values were slightly lower: $\mathrm{CF}$ $105,5 \mathrm{mmol} / \mathrm{L}$, non-CF $28 \mathrm{mmol} / \mathrm{L}$.

Median value of $24 \mathrm{mmol} / \mathrm{L}$ in healthy infants for the Macroduct test was found by the Liverpool group [13]. They performed both tests in 5-6 week old healthy infants. They reported excellent limits of agreement between the two methods. They showed that conductivity is as valid as QPIT in the age group $5-6 \mathrm{wk}$ and that chloride greater than $30 \mathrm{mmo} / \mathrm{L}$ should be assessed in a specialist CF Centre.

According to the Cystic Fibrosis Foundation (CFF) a patient having a conductivity result $\geq 50 \mathrm{mmol} / \mathrm{L}$ should be referred for QPIT sweat chloride analysis [10]. The manufacturer of the Sweat-Chek (Wescor) 
Table 3. Data for receiver operating characteristics curve for conductivity sweat test (Cut-off $=$ the concentration of $\mathrm{NaCl}$ in $\mathrm{mmol} / \mathrm{L}$. TP $=$ the number of true positive. $\mathrm{FN}=$ the number of false negative. $\mathrm{FP}=$ the number of false positive. $\mathrm{TN}=$ the number of true negative. PPV=positive predictive value. NPV=negative predictive value and kappa coefficient)

\begin{tabular}{|c|c|c|c|c|c|c|c|c|c|}
\hline Cut-off & TP & FN & FP & TN & Specificity & Sensitivity & PPV & NPV & Kappa \\
\hline 50 & 42 & 0 & 11 & 425 & 0.975 & 1 & 79.25 & 100 & 0.872 \\
\hline 51 & 42 & 0 & 10 & 426 & 0.977 & 1 & 80.77 & 100 & 0.882 \\
\hline 52 & 42 & 0 & 8 & 428 & 0.982 & 1 & 84.00 & 100 & 0.904 \\
\hline 53 & 42 & 0 & 8 & 428 & 0.982 & 1 & 84.00 & 100 & 0.904 \\
\hline 54 & 42 & 0 & 7 & 429 & 0.984 & 1 & 85.71 & 100 & 0.915 \\
\hline 55 & 42 & 0 & 7 & 429 & 0.984 & 1 & 85.71 & 100 & 0.915 \\
\hline 56 & 42 & 0 & 7 & 429 & 0.984 & 1 & 85.71 & 100 & 0.915 \\
\hline 57 & 42 & 0 & 7 & 429 & 0.984 & 1 & 85.71 & 100 & 0.915 \\
\hline 58 & 41 & 1 & 4 & 432 & 0.991 & 0.976 & 91.11 & 99.77 & 0.937 \\
\hline 59 & 40 & 2 & 3 & 433 & 0.993 & 0.952 & 93.02 & 99.54 & 0.935 \\
\hline 60 & 39 & 3 & 2 & 434 & 0.995 & 0.929 & 95.12 & 99.31 & 0.934 \\
\hline 61 & 38 & 4 & 0 & 436 & 1 & 0.905 & 100 & 99.09 & 0.945 \\
\hline
\end{tabular}

Table 4. Data for receiver operating characteristics curve for chloride titration sweat (Cut-off $=$ the concentration of $\mathrm{Cl}-$ in $\mathrm{mmol} / \mathrm{L}$. $\mathrm{TP}=$ the number of true positive. $\mathrm{FN}=$ the number of false negative. $\mathrm{FP}=$ the number of false positive. $\mathrm{TN}=$ the number of true negative. PPV=positive predictive value. NPV=negative predictive value and kappa coefficient)

\begin{tabular}{|c|c|c|c|c|c|c|c|c|c|}
\hline Cut-off & $\mathrm{TP}$ & FN & $\mathrm{FP}$ & $\mathrm{TN}$ & Specificity & Sensitivity & PPV & NPV & Kappa \\
\hline 34 & 44 & 0 & 11 & 422 & 0.975 & 1 & 80.00 & 100 & 0.876 \\
\hline 35 & 44 & 0 & 10 & 423 & 0.977 & 1 & 81.48 & 100 & 0.886 \\
\hline 36 & 44 & 0 & 9 & 424 & 0.979 & 1 & 83.02 & 100 & 0.897 \\
\hline 37 & 44 & 0 & 9 & 424 & 0.979 & 1 & 83.02 & 100 & 0.897 \\
\hline 38 & 44 & 0 & 8 & 425 & 0.982 & 1 & 84.62 & 100 & 0.907 \\
\hline 39 & 43 & 1 & 7 & 426 & 0.984 & 0.977 & 86.00 & 99.77 & 0.906 \\
\hline 40 & 43 & 1 & 4 & 429 & 0.991 & 0.977 & 91.49 & 99.77 & 0.939 \\
\hline 41 & 43 & 1 & 4 & 429 & 0.991 & 0.977 & 91.49 & 99.77 & 0.939 \\
\hline 42 & 42 & 2 & 2 & 431 & 0.995 & 0.955 & 95.45 & 99.54 & 0.950 \\
\hline 43 & 41 & 3 & 2 & 431 & 0.995 & 0.932 & 95.35 & 99.31 & 0.937 \\
\hline 44 & 41 & 3 & 1 & 432 & 0.998 & 0.932 & 97.62 & 99.31 & 0.949 \\
\hline 45 & 41 & 3 & 1 & 432 & 0.998 & 0.932 & 97.62 & 99.31 & 0.949 \\
\hline 46 & 41 & 3 & 1 & 432 & 0.998 & 0.932 & 97.62 & 99.31 & 0.949 \\
\hline 47 & 40 & 4 & 0 & 433 & 1 & 0.909 & 100 & 99.08 & 0.961 \\
\hline
\end{tabular}


Table 5. Suggested normal values for sweat tests

\begin{tabular}{|l|c|c|}
\hline \multicolumn{1}{|c|}{ Group } & $\begin{array}{c}\text { Sweat conductivity } \\
\mathrm{NaCl}[\mathrm{mmol} / \mathrm{L}\rfloor\end{array}$ & $\begin{array}{c}\text { Chloride titration } \\
\mathrm{Cl}^{-}[\mathrm{mmol} / \mathrm{L}\rfloor\end{array}$ \\
\hline Normal & $<50$ & $<34$ \\
\hline Borderline & $50-60$ & $34-46$ \\
\hline $\mathrm{Cl}:$ & $>60$ & $>46$ \\
\hline
\end{tabular}

recommends that conductivity results $<60 \mathrm{mmol} / \mathrm{L}$ are normal, $>80 \mathrm{mmol} / \mathrm{L}$ are positive for $\mathrm{CF}, 60$ to 80 $\mathrm{mmol} / \mathrm{L}$ are borderline [7]. Lezana suggested even narrower values for the conductivity method to diagnose or exclude CF $(90,75)$ [6].

Our infants values (Nanoduct) were: $>60 \mathrm{mmol} / \mathrm{L}$ confirmatory, value $<50 \mathrm{mmol} / \mathrm{l}$ negative, values $50-60$ $\mathrm{mmol} / \mathrm{L}$ corresponded to the equivocal range (Tab. 5). It proves, that as in the case of chloride concentration values, conductivity values are also different in the infant population.

\section{Chloride concentration}

Cut off values. A critical issue with regard to the sweat test in infants is the choice of cut-off values. The CFF consensus paper on the diagnosis of CF from 1998 supported the original Gibson and Cooke values, with a sweat chloride of $>60 \mathrm{mmol} / \mathrm{L}$ to be diagnostic, $>40 \mathrm{mmol} / \mathrm{L}$ in infants up to the age of 3 months as possible CF [10].

Those values, however, were found in CF NBS programmes not to be accurate in infants. Data from the Victorian NBS [14] found infants with sweat chloride in the 35-39 mmol/L range who had CF. An Australasian consensus statement recommended the following values for sweat chloride in infants following NBS: $\mathrm{Cl} \geq 60 \mathrm{mmol} / \mathrm{L}$ - cystic fibrosis, Cl 30-59 $\mathrm{mmol} / \mathrm{L}$ - borderline, $\mathrm{Cl} \leq 29$ - normal [15]. Lowering borderline cut-off to $30 \mathrm{mmol} / \mathrm{L}$ in infants following screening was also supported by Farrell et al. [16]. They found the mean sweat chloride in healthy infants to be $10.6 \pm 5.3 \mathrm{mmol} / \mathrm{L}$. (95\% CI, 9.9, 11.3) and in F508del carriers $14.9 \pm 8.3 \mathrm{mmol} / \mathrm{L}(95 \% \mathrm{CI}, 13.4$, 16.4)

Sweat chloride of $30 \mathrm{mmol} / \mathrm{L}$ was 4 standard deviations above healthy control infants and 2 standard deviations above F508del carriers. There is not such a difference between healthy controls and carriers in our data. We did not find statistically significant differences between healthy infants with no mutations and one mutation carriers.

Taking into consideration new data on sweat chloride tests results in healthy and $\mathrm{CF}$-affected infants emerging from NBS programmes, the CFF consensus from 2008 also updated sweat reference ranges for infants up to 6 months: $\leq 29 \mathrm{mmol} / \mathrm{L}, \mathrm{CF}$ unlikely; 30 $59 \mathrm{mmol} / \mathrm{L}$, intermediate; $\geq 60 \mathrm{mmol} / \mathrm{L}$, indicative of CF [17].

In Mackay's data, the variation between the chloride concentration obtained from the two different sides would suggest that, had only one side been tested, that up to 13 patients ( $4.4 \%$ of total group, $48 \%$ of those with at least one intermediate value) could be classified differently [18]. We agree that comparable results from sweat collected from two sites simultaneously permits improved confidence and is a useful internal quality control procedure, even more so, when two different methods are applied.

Observational group. An example of the complexity of mutation analysis is found in the evolving picture of individuals who are compound heterozygotes for CFcausing mutation and the $\mathrm{R} 117 \mathrm{H}$ mutation in the CFTR gene. The likelihood of CF in this group is driven by the length of a polythymidine tract in intron 8 of the $\mathrm{R} 117 \mathrm{H}$ allele. The presence of the $5 \mathrm{~T}$ tract in the $\mathrm{R} 117 \mathrm{H}$ background is usually associated with $\mathrm{CF}$, whereas $\mathrm{R} 117 \mathrm{H}(7 \mathrm{~T})$ is more often associated with isolated male infertility or pancreatitis [19]. But individuals from both groups may display sweat chloride values in the normal, intermediate or diagnostic range and some individuals with $\mathrm{R} 117 \mathrm{H}(7 \mathrm{~T})$ may present with CF lung disease. Thus $\mathrm{R} 117 \mathrm{H}(7 \mathrm{~T})$ is a mutation that when present in trans with a CF-causing mutation can cause a variable phenotype, ranging from normal to CF. Still unknown diagnosis was the reason to assess our analysed infants with $\mathrm{R} 117 \mathrm{H}(7 \mathrm{~T})$ as an observational group. There are ongoing discussions whether the $\mathrm{R} 117 \mathrm{H}$ variant should be included in CFTR mutation panels [20].

Borderline sweat tests. Infants with borderline sweat tests $(\mathrm{Cl} 34-46 \mathrm{mmol} / \mathrm{L}$ and Nanoduct $50-60 \mathrm{mmol} / \mathrm{L}$ ) after CF NBS pose a difficult problem as not all will turn out to have CF. These children should be seen by a physician experienced with $\mathrm{CF}$, the sweat test should be repeated at least twice on separate days. An extended mutation analysis should be performed.

Some CFTR mutations which are clearly "CF causing" (in particular, $3849+10 \mathrm{~kb} \mathrm{C}>\mathrm{T}$ ) are associated with normal or equivocal sweat electrolytes values. Close liaison with local molecular genetics is needed to determine these infants and to eventually include these mutations in CF NBS mutation panel [21,22].

Chest radiography, stool examination (faecal elastase), blood for electrolytes, albumin, liver function, fat-soluble vitamins may add to the clinical picture. We also recommend repeat assessment at 3-6 months of age (including another sweat test). We recognize that it is possible that some of these infants may not 
have clinical evidence of CF for many years. "Missing" these infants on NBS is an acceptable limitation of the programme that is by nature a screening programme

\section{Conductivity versus chloride concentration}

Our study confirms the results from previous studies, that conductivity is reliable diagnostic analytical procedure for $\mathrm{CF}[2,6]$.

Until now the conductivity method has not been accepted by the CFF or the National Committee for Clinical Laboratory Standards (NCCLS) as a definitive method for the disease [5], in spite of good agreement between conductivity and chloride titration found in several studies $[6,8,13]$. However, the methods used to assess conductivity as diagnostic tool (ROC curve, sensitivity, specificity, predictive values, kappa) clearly indicated also in our study that the conductivity method has an excellent capacity (certainly not worse than QPI) to discriminate between CF and non-CF subjects. We agree with the other studies, that conductivity might be as reliable as Quantitative chloride analysis to diagnose or exclude $\mathrm{CF}[6,12]$. Patients with equivocal values of conductivity had also equivocal QPIT values.

To our knowledge our work is the first to assess bilateral use of different sweat tests as a part of routine CF NBS protocol.

\section{Conclusions}

Because of the excellent capacity to discriminate between $\mathrm{CF}$ and non-CF subjects Nanoduct is a very useful tool in CF NBS protocol, allowing more timeefficient organization of the diagnostic and training procedures.

The new analyzing system is quick, simple and reliable and could be used as a diagnostic test in addition to screening.

It has a failure rate comparable to other sweat tests and could be used as a simple bedside test to confirm, exclude or suspect CF. In cases with borderline values other additional methods are indicated. The positive result should be always confirmed with another sweat test.

Simultaneous bilateral sweat testing with two different methods (concentration and conductivity) provides an extra quality control system.

We hope that our study provides some evidence based answer to the usefulness of conductivity relative to chloride results in real patients, coupled to CFTR mutation analysis in the context of developing world wide screening programmes.

Conflict of interest: The authors declare that there are no conflicts of interest.
Acknowledgements: Members of the Institute of Mother and Child Team for Cystic Fibrosis Newborn Screening: CF Clinic: Dr Barbara Radomyska, Professor Andrzej Milanowski, Dr Robert Piotrowski, Dr Katarzyna Walicka-Serzysko, Monika Mielus, Teresa Rutkowska, Ewa Bielińska; Screening Department: Iwona Lisewska, Aleksandra Pęciło, Ryszard Gląb, Agnieszka Kunkiewicz; Genetic Department: Dr Agnieszka SobczyńskaTomaszewska, Dr Kamila Czerska, Dr Aleksandra Norek, Dr Katarzyna Wertheim, Violetta Hryniewicz, Professor Jerzy Bal, Professor Tadeusz Mazurczak. The CF NBS program is funded by the Polish Ministry of Health

\section{References}

[ 1] Sands D, Zybert K, Ołtarzewski M et al. Newborn screening for CF in Poland. Pediatr Pol. 2008;83(6):624-633.

[2] Sands D, Piotrowski R, Nowakowska A, et al. Use of conductometric sweat test in diagnosis of cystic fibrosis in infants. Pediatr Pol. 2004;79(7):538-542.

[3] Gibson LE, Cooke RE. A test for concentration of electrolytes in sweat in cystic fibrosis of the pancreas utilizing pilocarpine iontophoresis. Pediatrics. 1959;23:158-161.

[4] Shwahman H, Mahmoodian A, Neff RK. The sweat test: sodium and chloride values. J Pediatr. 1981;98:576-8

[ 5] National Committee for Clinical Laboratory Standards. Sweat testing: sample collection and quantitative analysis; approved guideline. Publication No C34-A2. 2nd ed .Wayne, PA: NCCLS, 2000.

[ 6] Lezana JL, Vargas MH, Karam-Bechara J, Aldana RS, Furuya MEY. Sweat conductivity and chloride titration for cystic fibrosis diagnosis in 3834 subjects. J Cyst Fibros. 2003;2:1-7

[ 7] Sweat Chek conductivity analyser product sheet. Available at URL http://www.wescor.com/biomedical/html/sweat-chek. html. Accessed March 22, 2010.

[ 8] Barben J, Ammann RA, Metlagel, Schoeni MH. Conductivity determined by a new sweat analyzer compared with chloride concentrations for the diagnosis of cystic fibrosis. J Pediatr. 2005;146(2):159-62.

[ 9] Heeley ME, Woolf DA, Heeley AF. Indirect measurements of sweat electrolyte concentration in the laboratory diagnosis of cystic fibrosis. Arch Dis Child. 2000;82(5):420-4.

[10] Rosenstein BJ, Cutting GR. The diagnosis of cystic fibrosis: a consensus statement. Cystic Fibrosis Foundation consensus Panel. J Pediatr. 1998;132:589-595.

[11] Taylor CJ, Hardcastle J, Southern KW. Physiological measurements confirming the diagnosis of cystic fibrosis: the sweat test and measurements of transepithelial potential difference. Paediatr Respir Rev. 2009;10(4):220-6.

[12] Desax MC, Ammann RA, Hammer J, Schoeni MH, Barben J. Nanoduct sweat testing for rapid diagnosis of newborns, infants and children with cystic fibrosis. Eur J Pediatr. 2008; 167:299-304.

[13] Jayaraj R, Barton PV, Newland P, Mountford R, Shaw NJ, McCarthy E, Isherwood DM, Southern KW. A reference interval for sweat chloride in infants aged between five and six weeks of age. Ann Clin Biochem. 2009;46(1):73-8.

[14] Massie RJ, Olsen M, Glazner J, Robertson CF, Francis I. Newborn screening for cystic fibrosis in Victoria:10 years ' experience (1989-1998). Med J Aust. 2000;172:584-587.

[15] Massie J, Clements B. Diagnosis of cystic fibrosis after newborn screening: the Australasian experience -twenty years and five million babies later: a consensus statement from Australasian paediatric respiratory group. Pediatr Pulmonol. 2005;39:440-446.

[16] Farrell PM, Koscik RE. Sweat chloride concentration in infants homozygous or heterozygous for F508 cystic fibrosis. Pediatrics. 1996;97:524- 528. 
[17] Farrell PM, Rosenstein BJ, White TB et al. Guidelines for diagnosis of cystic fibrosis in newborns through older adults: Cystic Fibrosis Foundation consensus report. J Pediatr. 2008;153:S4-S14.

[18] Mackay RJ, Florkowki CM, George PM, Sies CW, Woods S. Uncertainty of sweat chloride testing: does the right hand know what the left hand is doing. Ann Clin Biochem. 2008;45:535-538.

[19] Kiesewetter S, Macek M, Davis C, et al. A mutation in CFTR produces different phenotypes depending on chromosomal background. Nat Genet. 1993;5:274-8.

[20] Scotet V, Audrézet MP, Roussey M, Rault G, Dirou-Prigent A, Journel H, Moisan-Petit V, Storni V, Férec. Immunoreac- tive trypsin/DNA newborn screening for cystic fibrosis: should the R117H variant be included in CFTR mutation panels? Pediatrics. 2006;118(5):1523-9.

[21] Mayell SJ, Munck A, Craig JV, et al. A European consensus for the evaluation and management of infants with an equivocal diagnosis following newborn screening for cystic fibrosis. J Cyst Fibros. 2009;8:71-78.

[22] Castellani C, Southern KW, Brownlee K, et al. European best practice guidelines for cystic fibrosis neonatal screening. J Cyst Fibros. 2009;8:153-173.

Submitted: 8 May, 2010 Accepted after reviews: 22 June, 2010 